ERGONOMICS, 2000, vOL. 43, NO. 8, 1052-1075

\title{
Teamwork in multi-person systems: a review and analysis
}

\author{
Carol R. Paris $\dagger$, Eduardo Salas $\ddagger^{*}$ and Janis A. CANnON-Bowers $\dagger$ \\ $\dagger$ Naval Air Warfare Center Training Systems Division, Code 496112350 \\ Research Parkway, Orlando, FL 32826-3224, USA
}

$\ddagger$ Department of Psychology, University of Central Florida, PO Box 161390, Orlando, FL 32816-1350, USA

Keywords: Teamwork; Team performance; Team training; Team effectiveness; Teams.

\begin{abstract}
As the scope and complexity of modern task demands exceed the capability of individuals to perform, teams are emerging to shoulder the burgeoning requirements. Accordingly, researchers have striven to understand and enhance human performance in team settings. The purpose of this review is to summarize that research, from the theoretical underpinnings that drive it, to the identification of team-level elements of success, to the methodologies and instruments that capture and measure those characteristics. Further specified are three important avenues to creating successful teams: team selection, task design and team training. In other words, one can select the right people, provide them with a task engineered for superior performance and train them in the appropriate skills to accomplish that task. Under task design, new technologies and automation are examined that both support and impede team functioning. Finally, throughout are provided critical remarks about what is known about teamwork and what is needed to be known to move the science and practice of team performance forward. The paper concludes with the identification of team issues that require further investigation.
\end{abstract}

\section{Introduction. What are teams? What is teamwork?}

Transforming teams of experts into expert teams necessarily begins with an understanding of what characteristics uniquely define the team and set it apart from small groups. Teams are more than collections of individuals and teamwork is more than the aggregate of their individual behaviours. Moreover, one cannot simply label a group of individuals a 'team' and expect that they will perform as a team (Bass 1980). Specifically, one may conceive a team to be a 'distinguishable set of two or more people who interact dynamically, interdependently, and adaptively toward a common and valued goal/objective/mission, who have each been assigned specific roles or functions to perform, and who have a limited life-span membership' (Salas et al. 1992: 4). Characteristics that distinguish teams from small groups include the following: multiple sources of information, task interdependencies, coordination among members, common and valued goals, specialized member roles and responsibilities, task-relevant knowledge, intensive communication, and adaptive

*Author for correspondence; e-mail: esalas@pegasus.cc.ucf.edu 
strategies to help respond to change (Dyer 1984, Modrick 1986, Morgan et al. 1986, Salas and Cannon-Bowers 1997). To understand effective team performance or 'teamwork', one must understand how groups of individuals function to produce effectual synchronized output, rather than just summed or aggregated responses (Steiner 1972, Hackman and Morris 1975, Nieva et al. 1978, Meister 1985, Fleishman and Zaccaro 1992). But, what precisely is 'teamwork'?

\section{Theoretical developments}

The first serious attempts to study team processes began in the 1950s and 1960s, with a focus largely on military teams and team processes that enabled them to function more effectively under conditions of extreme time pressure, high stress, ambiguous and incomplete information, and severe consequences for actions taken. Much of the impetus for team research over the years has been tied to team failures, particularly those associated with high visibility (e.g. aircraft accidents, military accidents) (Ilgen 1999).

\subsection{Evolving perspectives}

The last half-century has produced theories that encompass many different perspectives. Although team theories began as descriptive efforts, many have evolved over time to provide more normative guidance for improving teams. Most theories have incorporated a general input-process-output approach, whereby certain variables are fed into the system (e.g. environmental and organizational variables, individual input variables, and team input variables), team processes follow (e.g. orientation, communication, adaptation, etc.), and team output (productivity) results. Some models incorporate dynamic change through feedback loops, emanating primarily from the output side and feeding back to the input or process components (Ilgen 1999).

Although detailed descriptions of the many theories, models, and taxonomies are beyond the scope of this effort, representative theories contributing to our understanding of the teamwork fall into eight primary categories. These are captured in table 1 .

\subsection{Validation of competencies}

In addition to developing theories and models, team researchers have struggled to identify those critical skills or traits that enable teams to coordinate, communicate, strategize, adapt, and synchronize task relevant information so that they can fulfil their goals and missions. In the 1970s, research focused on orientation, resource distribution, timing, response coordination, motivation (Nivea et al. 1978), and team morale (Ruffell-Smith 1979).

In the 1980s, emphasis was given to collective self-efficacy (Bandura 1986), implicit or explicit coordination activities (Kleinman and Serfaty 1989), and providing tasks and motivational reinforcement (Oser et al. 1989). Morgan et al. (1986) highlighted seven specific skill dimensions - giving suggestions or criticisms, cooperation, communication, team spirit and morale, adaptability, coordination, acceptance of suggestions or criticism.

Finally, in the 1990s, the most significant teamwork competencies were thought to be mutual performance monitoring (Hackman 1990), belief in the importance of teamwork (Gregorich et al. 1990), collective orientation (Driskell and Salas 1992), adapting to novel and unpredictable situations (Prince and Salas 1993), exhibiting 
Table 1. Theoretical contributions to the teamwork concept.

Representative theories

Social psychological approach: pertaining to the social and psychological implications of team members' relationships/interactions with one another

Interaction Processes (Hackman and Morris 1975)

Normative Model of Group Effectiveness (Hackman 1983, 1987)

Sociotechnical approach: concerning the technical and work-related implications of team members' relationships and interactions with one another

Dynamic Interactions (Kolodny and Kiggundu 1980)

Self-Regulating Work Groups (Pearce and Ravlin 1987)

Ecological approach: relating to the spacing and interdependence of team members and institutions, or the relationships of team members with their organizational or working environment

Group and Organizational Boundaries (Sundstrom and Altman 1989, Sundstrom et al. 1990)

Human resource approach: focusing on the utilization of human capabilities and talents Human Resource Management (Shea and Guzzo 1987)

Technological approach: relating to industry or applied science, or to technological progress Technological and Organizational Variables (Goodman et al. 1987)

Lifecycle approach: pertaining to changes within a team that result from its maturation or evolution over a lifecycle

Time and Transition Model (Gersick 1985, 1988)

Team Evolution and Maturation Model (TEAM) (Morgan et al. 1986, Morgan et al. 1994)

Functional (taxonomic) or task-oriented approach: concerning team roles, functions, or tasking

Team Performance Model (Nieva et al. 1978; others = Dickinson 1969, Dieterly 1988, Fleishman and Zaccaro 1992, Naylor and Dickinson 1969, Shiflett et al. 1982

Integrative approach: inclusive of multiple approaches or models

Composition, Structure, Resources and Process, or Task Group Effectiveness Model (Gladstein 1984)

Input, Throughput, Output or Team Effectiveness Model (TEM) (Tannenbaum et al. 1992)

Work Team Design (Campion et al. 1993, Campion et al. 1996)

flexibility (Prince and Salas 1993), potency (Guzzo et al. 1994), cohesion (Mullen and Copper 1994), performing self-correction (McIntyre and Salas 1995), using closedloop communication (McIntyre and Salas 1995), exhibiting assertiveness (SmithJentsch et al. 1996b), predicting each others' behaviour (Volpe et al. 1996), and four specific skill dimensions (information exchange, communication, supporting behaviours, and team initiative/leadership) (Smith-Jentsch et al. 1998a,b). Recently, Cannon-Bowers et al. (1995) and Salas and Cannon-Bowers (2000) summarized teamwork dimensions into three primary categories: cognitions, skills and attitudes. Cognitions (or knowledge) include cue strategy associations, task specific team-mate characteristics, shared task models, team mission, objectives, norms, and resources, task sequencing, accurate task models and problem models, team role interaction patterns, teamwork skills, boundary spanning roles, and team orientation. Behaviours (or skills) consist of adaptability, shared situational awareness, mutual 
performance monitoring, motivating team members/team leadership, mission analysis, communication, decision-making, assertiveness, interpersonal coordination, and conflict resolution. Last, attitudes embody motivation, collective efficacy/ potency, shared vision, team cohesion, mutual trust, collective orientation and importance of teamwork.

Although to date, much of the theoretical development and research has rested largely within the central process component of team models, a new trend is emerging. One is witnessing an increasing interest in issues facing organizational teams, and with that interest comes a shift in research and theoretical development to the inputs and outputs that bound, constrain, and impact team processes within organizations (Ilgen 1999).

\subsection{Hallmark of the nineties: the shared mental model}

Team research in the 1990 s has also evolved to a great extent around another theoretical development - one which constitutes a significant and unifying thread underlying much of the current work in this field. This is the concept of the shared mental model (Cannon-Bowers et al. 1993). Mental models are knowledge structures, cognitive representations or mechanisms (e.g. mental simulations) which humans use to organize new information, to describe, explain and predict events (Rouse and Morris 1986), as well as to guide their interaction with others (Rumelhart and Ortony 1977, Gentner and Stevens 1983). A team mental model would reflect the dependencies or interrelationships between team objectives, team mechanisms, temporal patterns of activity, individual roles, individual functions, and relationships among individuals. Shared mental models allow team members to implicitly and more effectively coordinate their behaviours, i.e. they are better able to recognize the individual responsibilities and information needs of team-mates, monitor their activities, diagnose deficiencies, and provide support, guidance, and information as needed (Orasanu 1990, Entin et al. 1994, Duncan et al. 1996). More about mental models will be detailed below.

Because theoretical foundations ground our understanding of team variables and processes, they enable us to target critical skills to be measured. This is a significant first step in improving team performance. Theories of team performance abound in the literature. And our understanding of what variables affect team performance has greatly improved over the years. However, it is suggested that at this point in time more theories are not necessarily better. That is, it is believed that there are probably enough theories and models. The field needs richer, deeper and better specified models (and validated!) of team performance to more precisely guide measurement and training efforts.

\section{Measurement of team performance}

Without the measurement of team performance, one could not ascertain the success of any intervention to improve it, whether that intervention is training, automation, or other. Team-level measurement, however, presents a significant challenge.

\subsection{The challenge}

To assess teamwork skills, one must capture the dynamic, multilevel nature of teamwork, a process which is neither simple nor straightforward (Salas and CannonBowers 1997). Teamwork (or process) skills are not readily quantifiable, as are team inputs and outputs (Baker and Salas 1992). Moreover, team behaviours evolve over 
the life-cycle of a team. Teamwork behaviours, resulting from team member interactions, need to be differentiated from taskwork behaviours, which are the position-specific behaviours of individual team members (Morgan et al. 1986, 1994).

\subsection{Team task analysis: a prerequisite}

Prerequisite to the measurement of team performance is the team task analysis. A team task analysis provides information about team learning objectives and team competencies needed. It identifies the cues, events, actions, coordination demands, and communication flows needed for effective teamwork. It enables the understanding of the nature of task interdependency in teamwork and to distinguish collective team tasks from individual tasks (Salas and Cannon-Bowers 2000). However, not yet available is a sound, validated and systematic methodology for analysing team tasks. Some work is now going on and still under development (Annett 1997, Swezey et al. 1998).

\subsection{Instrument criteria}

To measure teamwork effectively, the chosen instrument should be theoretically based, psychometrically sound, and a practically useful indicator of teamwork (Baker and Salas 1992). Team assessment tools should: (1) identify processes linked to key team outcomes, (2) distinguish between individual and team level deficiencies, (3) describe interactions among team members so as to capture the moment-tomoment changes that occur, (4) produce assessments that can be used to deliver specific performance feedback, (5) produce evaluations that are reliable and defensible and (6) support operational use. Metrics that fulfil these criteria will assess, diagnose and remediate important skill deficiencies. To review specific principles guiding team performance measurement, see Baker and Salas (1992) and Salas and Cannon-Bowers (2000).

\subsection{Selecting the appropriate measures/methodologies}

No single measure of performance will be appropriate for all purposes. The primary types of measures are: (1) descriptive measures, which describe what is happening at any given time and seek to document individual and team behaviours by highlighting crucial points of interaction and moment-to-moment changes in team functioning; (2) evaluative measures, which judge performance against identifiable standards and serve to answer questions of effectiveness; and (3) diagnostic measures, which seek to identify the causes of behaviour and question how and why things occurred as they did. Diagnostic measures contribute inputs to the feedback process necessary to improve subsequent performance (Cannon-Bowers and Salas 1997).

The measures for assessing team skills generally fall into two categories:

- Team versus individual measures: individual (taskwork) measures assess the knowledge/skills required to perform individual tasks and meet individual responsibilities. Teamwork measures focus on coordination requirements between team members, such as backup, mutual performance monitoring/ error correction, information flow, etc.

- Outcome versus process measures: although successful outcomes demonstrate that training objectives have been met, a focus on how the task was accomplished (i.e. process measurement) is important for diagnosing performance problems that may someday obstruct or prevent desired 
outcomes. Because flawed processes occasionally result in successful outcomes, it becomes necessary to measure both processes and outcomes if one is to ensure consistently effective performance. Process measures generally depend on observation by skilled raters. They might include analysis of team communications or information flow, analysis of interactions or strategies employed by team members, interviews, field observation techniques, task analysis, modelling or computerized simulation of teams, and mathematical indices of team processes (Dyer 1984, Meister 1985). When outcome measures are used, they typically rely on expert opinion or automated performance recording. They might include ratings of proficiency with respect to timeliness (latency), accuracy/errors, number and type of omitted or incomplete tasks, frequency counts, and measures of knowledge (Dyer 1984). Processes and outcome measures complement one another, and when provided at both the individual and team levels, provide the most complete picture of team performance (table 2).

Measurement approaches for team evaluation range from developing/applying critical events or event-based techniques to modelling human performance via expert systems, neural networks, fuzzy sets, or mathematical models (e.g. Petri nets). Data may be captured online by observers or via automated systems (the team outcome). Instruments include rating or event-based scales, observational checklists, critical incident analysis, communication analysis, employee surveys and debriefing procedures. While progress has been made in designing measurement techniques and tools, more work is needed. And maybe a shift in focus is more appropriate. One needs to develop more dynamic measurement systems that allow for on-line assessment of teamwork. The technology (e.g. human performance modelling) is maturing, but more work is required. The current focus on checklists, while useful, does not capture fully the dynamic nature of teamwork.

\section{Approaches for enhancing teamwork: variables that shape our interventions}

There are theoretical models to explain the teamwork process. One has a sense of the most important teamwork competencies. Finally, there are measurement techniques and tools to diagnose a team's deficiencies. So how can one apply this knowledge to enhance the way teams perform? The remaining discussion will focus on three interventions - team selection, task design and training — that can be utilized to

Table 2. Taxonomy of human performance measures.

Individual Team

Process

- Cognitive processes

- Position-specific taskwork skills

Outcome

- Accuracy

- Latency
- Information exchange

- Communication

- Supporting behavior

- Team leadership

- Mission effectiveness

- Aggregate latency and accuracy

From Canon-Bowes and Salas (1997), 56 Copyright 1997 by Lawrence Erlbaum Associates. Adapted with permission. 
increase a team's functioning. Before one can plan methods for improving team performance, however, one must first evaluate those factors (input and process variables) that impinge on it. Table 3, adapted from the taxonomies of Morgeson et al. (1997) and Meister (1985), enumerates the most significant of these.

Configuration of table 3 factors serves to influence, positively or negatively, the manner in which a team performs. With these determinants in mind, the first intervention - team selection — is presented.

\subsection{First approach: team selection}

One of the first things to be done to ensure successful team performance is to select the right team members. If stable individual characteristics associated with superior abilities for team coordination and performance can be identified, then steps to select the right people can be made.

4.1.1. Individual traits: Traditional staffing processes, which normally determine position requirements, recruit applicants, then assess and select those most qualified to perform the job, are not entirely adequate for populating teams. Teams require special staffing considerations. Initially, one would need to consider how staffing requirements might vary according to team type and function. For example, consider

Table 3. Taxonomy of variables influencing team performance.

\begin{tabular}{|c|c|c|c|}
\hline Factor(s) & Description & Examples & $\begin{array}{l}\text { Applicable } \\
\text { intervention(s) }\end{array}$ \\
\hline $\begin{array}{l}\text { Contextual } \\
\text { factors }\end{array}$ & $\begin{array}{l}\text { Variables that pertain to the } \\
\text { environment in which the } \\
\text { team activity is embedded }\end{array}$ & $\begin{array}{l}\text { Culture } \\
\text { Climate } \\
\text { Training/education } \\
\quad \text { systems } \\
\text { Reward systems } \\
\text { Information systems }\end{array}$ & $\begin{array}{l}\text { Team selection } \\
\text { Task design } \\
\text { Training }\end{array}$ \\
\hline $\begin{array}{l}\text { Structural } \\
\text { factors }\end{array}$ & $\begin{array}{l}\text { Variables impinging primarily } \\
\text { from sources external to the } \\
\text { team, but may include some } \\
\text { internal to the team (e.g. } \\
\text { team organization) }\end{array}$ & $\begin{array}{l}\text { Physical environment } \\
\text { Organizational } \\
\text { arrangements } \\
\text { Technological systems }\end{array}$ & $\begin{array}{l}\text { Task design } \\
\text { Training }\end{array}$ \\
\hline $\begin{array}{l}\text { Team design } \\
\text { factors }\end{array}$ & $\begin{array}{l}\text { Variables inherent to the team } \\
\text { itself }\end{array}$ & $\begin{array}{l}\text { Work design } \\
\text { Task interdependence } \\
\text { Team size/composition } \\
\text { Leadership }\end{array}$ & $\begin{array}{l}\text { Team selection } \\
\text { Task design } \\
\text { Training }\end{array}$ \\
\hline $\begin{array}{l}\text { Process } \\
\text { factors }\end{array}$ & $\begin{array}{l}\text { Variables inherent to the team } \\
\text { itself and the way in which it } \\
\text { functions }\end{array}$ & $\begin{array}{l}\text { Boundary management } \\
\text { Task cohesion } \\
\text { Performance norms } \\
\text { Communication } \\
\text { Team interactions } \\
\text { Potency/team self-efficacy } \\
\text { Team spirit }\end{array}$ & $\begin{array}{l}\text { Team selection } \\
\text { Task design } \\
\text { Training }\end{array}$ \\
\hline $\begin{array}{l}\text { Contingency } \\
\text { factors }\end{array}$ & $\begin{array}{l}\text { Variables impinging from } \\
\text { sources internal and external } \\
\text { to the team }\end{array}$ & $\begin{array}{l}\text { Team application/mission } \\
\text { Resource availability } \\
\text { Procedural requirements } \\
\text { Rules of operation, } \\
\text { managing, or decision- } \\
\text { making }\end{array}$ & $\begin{array}{l}\text { Task design } \\
\text { Training }\end{array}$ \\
\hline
\end{tabular}


the following types of teams: command and control teams, production teams, customer service teams, professional/technical decision-making teams, and executive teams. What types of traits or skills are needed for each — functional flexibility or highly specialized skills? Ability to deal with people and handle personal dynamics? Ability to deal with poorly defined problems? Once a determination is made with respect to basic abilities, team staffing requires that one goes further and address how selection choices may influence performance outcomes of the team as a whole. There is a need, therefore, to understand not only individual effectiveness, but also team effectiveness as well, and to evaluate probable interactions between group-and individual-level factors. This is where the theories and models of team effectiveness presented earlier provide some basis for action.

Success depends not only on knowledge, skills and attitudes (KSA) required for individual task performance, but also on those traits of individual team members that facilitate team interaction and functioning (e.g. learning ability, initiative, risktaking propensities, adaptability, tolerance for stress, etc.). These characteristics are critical for teams that require more coordination, such as command and control teams and traditional assembly line (production) teams. They are less important in collaborative tasks where team interaction is less restricted. Similarly, service teams would look on the ability to adapt team tasks to environmental demands as a desirable attribute. Leadership qualities influence the performance of all teams, whether they are exhibited by formally appointed leaders, or by non-appointed, emerging leaders (Klimoski and Jones 1995).

4.1.2. Team size: Team selection involves establishing appropriate team size. This becomes problematic when the task has not been performed before, or when it is artificially constrained by such factors as leader preferences, available resources, or the number of people free to participate. If too few people are chosen, undue stress will be placed on team members; on the other hand, if too many are chosen, resources are wasted (Klimoski and Jones 1995). Size is largely fixed by the nature of the tasks to be performed. It limits the manner in which the team can be organized and how it can interact. Empirical evidence suggests that group productivity is not a linear function of group size, but that a negatively accelerated function generally exists between the two, that is, larger teams tend to be detrimental to effectiveness, typically as a result of heightened coordination needs (Kidd 1961, George et al. 1963, Steiner 1972, Gladstein 1984, Sundstrom et al. 1990). As a general rule, teams should be staffed to the smallest number needed to do the work (Hackman 1987, Sundstrom et al. 1990).

\subsubsection{Team composition: Not only size, but aspects of team composition must also} be determined. Specifically, team composition may vary along several dimensions: (1) attributes such as age, gender, race, intelligence, aptitude, training, experience, personality, etc., (2) distribution of these attributes within the team and (3) the stability of team composition over time. Among the issues to be raised are: (1) the effects of team homogeneity/heterogeneity, compatibility and turnover, (2) the degree of redundancy that exists between team functions and (3) the extent to which team output is related to individual performances. With respect to the latter, the more individual performance determines team output, the less important become the team processes, and the less necessary it becomes to provide special team training (Meister 1985). 
4.1.4. Team stability: Team stability was mentioned above. Because individual skill is a major determinant of team performance, the effects of adding untrained personnel as replacements are likely to be adverse. While adding skilled replacements may show a positive effect, that effect tends to be smaller than the negative impact resulting from fewer skilled replacements. As a general rule, there is little disruption of team performance from turnover, as long as only one team member is replaced at a time and that replacement is as skilled as the person he replaces. Disruption is increased if additional team members are replaced (Naylor and Briggs 1965, Meister 1985). Teams composed of $40 \%$ or more untrained individuals demonstrate declining performance (Morgan et al. 1978), and the greatest effect on performance is likely to come from changes in key or central positions (Ziller 1963, Trow 1964).

4.1.5. Select or train?: Selection becomes important in areas where training is unlikely to have an effect. For example, training may influence an individual team member's attitudes, but not his personality traits. Attitudes, or learned patterns of behaviour, are more or fewer modifiable through training. Personality traits, on the other hand, are 'by definition' stable, deeply rooted predispositions to respond in predictable ways. As such, they may be resistant to change through training and hence become an issue for selection. In short, personality traits limit training effects and constrain what may be accomplished with a particular individual (Prince et al. 1992).

4.1.6. Predicting team productivity: It is important to establish the mix, or level, of the particular KSA that may be appropriate for a team. For some tasks (e.g. production or manufacturing tasks), team performance is influenced by the ability of the least capable person. In these situations, homogeneous teams may be a better arrangement than heterogeneous teams. Although teams with lower ability may produce less, their lower output can be compensated by the greater output of higher ability teams, provided the latter are not adversely affected by a single member of less ability. The assessment of key attributes, such as team orientation, responsibility, task focus, commitment, and interpersonal compatibility are hard to define and measure. Much work remains to be done in the area of developing construct-valid and practical instruments that can measure these traits or qualities. There is hope that through the alignment of team member similarities and differences, one may begin to predict team productivity (Prince et al. 1992, Klimoski and Jones 1995).

Again, traditional staffing processes are not adequate for team member selection. One cannot simply identify necessary KSA at the individual level, choose candidates that meet those criteria, then hope that the team will perform as planned. Teams present new challenges. And these challenges have to be met with new approaches to select individuals to function in teams. This is evident, not only in team selection, but also for task design.

\subsection{Second approach: task design}

If characteristics of the task can be found to facilitate or inhibit team coordination, then tasks can be redesigned. Task design variables include such things as automation, workload, time pressure, governmental regulations, organizational policies, established procedures, team structure, etc. Campion et al. (1993, 1996) determined that job design ranked second, below team processes, but above interdependence, context, and composition, as important variables influencing team 
effectiveness. These authors proposed specific advice for task design. First, management should make jobs motivating by encouraging autonomy, wide participation in team decisions, a variety of task assignments, and interdependence between team members. Management should create a supportive context for the team in terms of training, resources, information, and encouragement, and should monitor and encourage positive team processes. Some of the key design targets that have been investigated to date are discussed below.

\subsubsection{Workload/time constraints: Workload is a consideration because even one} overloaded team member, by neglecting his obligations to fellow team members, could impact the performance of the team as a whole (Roby and Lanzetta 1957a,b, Dyer 1984). Level of workload may also determine which team processes are needed for team performance and which training interventions will be most useful for those situations (Kleinman and Serfaty 1989, Bowers et al. 1992). Time pressure, which is closely tied to workload, is negatively correlated with the reliability of decisionmaking. As time pressure increases, the reliability of team decision-making drops (Adelman et al. 1986).

\subsubsection{Team architecture/structure: Team architecture (TA) refers to those system} or task variables that define or influence how team members interact. At least three variables are hypothesized to constitute TA: member proximity, communication modality, and the allocation of functions to individual team members (Urban et al. 1995).

Member proximity involves both physical and psychological distance. Team cohesiveness and communication fluctuate as a function of physical distance. Generally, when physical distance is smaller, cohesiveness and communication are positively affected. Greater distances tend to exert negative influences. Team decision-making and coordination are ultimately affected. Psychological distance is a perceptual phenomenon brought about by chain-of-command or status differences, both of which may also be related to physical distance. Psychological distance operates in much the same manner as physical distance, resulting in decreased communications as the perceived distance grows (Urban et al. 1995).

Communication modality refers to the nature of the medium through which team members engage in their interactions. The most prevalent modality is face-to-face verbal interaction. Other modalities include paper-mediated, audio-mediated, computer-mediated, and video-mediated communication. Team processes, team decisionmaking, and team coordination may all be differentially impacted by these modalities. For example, interacting via computers tends: (1) to limit severely the social context cues (visual feedback and statu s cues) that are available in face-to-face communication, (2) to constrain the depth of discussion and analysis that is likely to occur and (3) to increase the time needed for groups to make a decision. On the other hand, computer-mediated interaction tends to obscure status differences, resulting in greater participation by members and possibly better team coordination (Urban et al. 1995).

Team structure or organization refers to the assignment of particular components of the team's collective task to individual team members and to the nature of the interactions that must ensue for the team to effectively coordinate and execute those tasks. A team's organization, as well as its ability to adapt to various system loads, is largely a function of the dependency relationships between tasks and operators. Tasks may be performed independently, sequentially, or in parallel. If 
task/operator dependency is low, organization is relatively unimportant, i.e. inadequate performance at one position will have little effect on other operator positions. If dependency is high, inadequate performance at one operator station will seriously affect another (dependent) station, and this effect may be amplified by the nature of the organization. In this sense, team organization determines team output. Serially structuring a team will expose it to the distinct possibility of system overload since its performance is determined by the weakest link in the chain (Meister 1985). A team's organization and task dependencies influence how team members interact. Research has investigated whether those interactions can be objectively specified or trained, and has spawned practical guidelines (Swezey and Salas 1992a,b).

Teams communicate differentially in response to the demands imposed by team structure. Consider, for example, how distributed team structures might have important implications for member coordination and communication (Kleinman and Serfaty 1989). Similarly, consider, non-hierarchical teams, where there is at least some degree of overlap in responsibilities. Team members in those types of teams communicate more than those in hierarchical teams, where there is no overlap in team responsibilities. Additionally, non-hierarchical teams perform more effectively than hierarchical teams, at all workload levels. These results suggest that nonhierarchical structures facilitate more effective team coordination and decisionmaking than hierarchical structures (Bowers et al. 1992, Urban et al. 1995).

\subsubsection{Technology: Of all the variables to be investigated in the human engineering} of teams, particularly of those related to task design, one of the most influential is that of technology. Consider just a few of the advances that have become part of everyday life for many teams: telecommunications (where geographically separated team members can communicate electronically to solve problems or to perform simulated tasks in virtual environments), networked simulations, distance learning, multimedia technology, interactive courseware, and even intelligent systems. In spite of the tremendous promise of technology and automation, in team settings these advancements have ironically yielded much disappointment (Wiener et al. 1991, Thornton et al. 1992, Morgan et al. 1993, Bowers et al. 1996).

Team tasks are at significant risk when automated technologies are introduced. Automation effects operating at the individual level may become compounded when distributed across teams. As automation wholly or partially replaces team functions, team structure and composition change, team roles are unavoidably redefined, and interaction and communication patterns are altered (Bowers et al. 1993, Weiner 1993, Jentsch et al. 1995, Bowers et al. 1996, Mosier and Skitka 1996). While it has been assumed that reductions in workload would accompany automation, this benefit has not been wholly realised. Automation frequently replaces physical activity with cognitive and perceptual activity, leaving workload levels unchanged. Additionally, situational awareness (SA) may decline. SA is a decision-maker's moment-by-momen $t$ ability to monitor and understand the state of a complex system and its environment (Adams et al. 1995, Morrison et al. 1998). SA may decline as a result of (1) monitoring demands and subsequent vigilance decrements, (2) complacency due to over-reliance on automation, (3) system complexity, (4) poor interface design, (5) inadequate training, or even (6) lack of trust in automation (Endsley 1997). If operators lose SA, they may fail to notice system anomalies, may intervene prematurely, may use improper procedures, and may not supply the appropriate intervention should automation fail. Given that automation may not 
reduce workload and may compromise SA, it may not be desirable to implement full automation in team tasks, even if that is technically possible. Endsley (1997) recommends that intermediate levels of automation may be preferable for certain types of tasks or functions to keep SA at a higher level and allow human operators to perform critical functions.

Automation also makes possible interactive training, which may now be provided through distributed simulations linked via local or wide area networks. Salas and Cannon-Bowers (1997) caution, however, that such simulations need to link specific task requirements to team training needs to create effective learning environments (explanation of event-based approaches to training in Dwyer et al. 1997). Training simulators may also be embedded in operational equipment so that they can provide instructional opportunities when operators are not busy performing their tasks. Sophisticated systems, capable of capturing multiple forms of performance data (eye movements, communications, keypress actions), diagnosing performance, and providing on-line feedback, now exist (e.g. Zachary and CannonBowers 1997, Zachary et al. 1997a,b).

Besides their training value, computer systems may expedite decision-making in team settings. Decision-making at the team level multiplies those limitations inherent in human decision-making at the individual level. Decision support systems (DSS) can aid the decision-maker by reducing problem complexity and associated memory load, and by enhancing SA. An example of current work in this area may be found in the TADMUS (Tactical Decision-Making Under Stress) DSS being designed for Naval command and control environments. This DSS organizes and presents tactical data in a form that is consistent with experts' usage, and guides decision-makers through the huge amount of tactical data which they need to process (see Morrison et al. 1998, for a description of this system). In business settings, DSS (called group decision support systems, or GDSS) support tasks with pooled interdependencies that require discussion and communication. They are typically utilized in decision rooms, local decision networks, teleconferencing, and remote decision-making. While most evidence supports the use of decision support in group settings, i.e. decision quality is increased, some research suggests that decision aids may isolate operators from each other's SA and decision-making processes, thereby reducing redundancy and human input, and increasing the possibility of errors (Mosier and Shitka 1996). Bowers et al. (1996) suggest that team decision-making imposes additional requirements on decision-makers due to the distributed nature of the information, and that making effective use of that information requires that one develops techniques to integrate what is necessary and vital to the decision-making task.

For better or for ill, the requirements for teams to operate with automated systems will likely increase with time. Clearly, that technology can guarantee neither greater effectiveness nor efficiency in the way teams perform. Given that automation effects are both compounded and confounded at the team level, it becomes imperative that engineering efforts to optimize team performance account for their potential impact. Taking the time to address this, as well as the impact of other task design variables, may enable us to ameliorate many foreseeable deficiencies in the way teams are likely to conduct their tasks.

\subsection{Third approach — team training}

If the knowledge, skills, and strategies used to facilitate team coordination or effective performance can be identified, then teams can be trained. Training serves to 
automate controlled behavioural processes. Automating these behaviours makes them more resilient to the effects of stress, thus bolstering performance under stressful conditions. It is easy to understand, then, why the demand for team training has skyrocketed over the last 15 years, given the exponential growth in the number of teams over that same period. Fortunately, great strides have been made since the mid-1980s, when team training suffered many deficiencies (e.g. too few training methods/strategies that had been evaluated for their applicability to teams, few, if any, quantitative performance standards for team tasks and skills, lack of specificity in feedback to teams and individuals) (Modrick 1986). Researchers are now more able to define what competencies need to be trained, as well as how to train them (e.g. Dyer 1984, Swezey and Salas 1992a,b, Wiener et al. 1993, Guzzo and Salas 1995, Salas et al. 1995, West 1996, Cannon-Bowers and Salas 1998).

\subsubsection{What to train: Until recently, team performance has been considered to be a} function of the average skill level of the individuals who comprise the team. While individual skills are unquestionably necessary to team success, they are not sufficient (Salas et al. 1992). Process losses, resulting from interruptions in the flow of communication or coordination behaviours, are likely to threaten performance if teamwork skills are not adequately developed (Steiner 1972). One can maximize training efficiency by combining individual and team skills training into a single training design and by allocating the appropriate amount of individual skills training relative to team skills training. Additionally, one can tailor the sequence in which each type of training is be presented (i.e. train individual skills first), as well as the time that should be allowed to elapse between individual and team skills training (Salas et al. 1992). Finally, the skills that are targeted for training should meet specific criteria, namely: (1) they have been empirically demonstrated to have an effect on team success, (2) they are difficult to learn, (3) they require more than simple repetition for development, (4) they require practice to prevent their loss and (5) they may be infrequently required, but are essential for survival (Dyer 1984).

Cannon-Bowers et al. (1995) proposed a framework that contributes some useful insights into selecting the appropriate competencies for training. The competencies may be specific to a particular task or team, or they may be generic in that they apply across teams or tasks. To ascertain what competencies must be trained, one would begin by asking certain questions: Are the members of this team the same individuals over time? Is the membership fairly stable? Does the team perform the same or similar tasks over time? Are the tasks fairly stable? The answers to these questions will align the required competencies into one of four categories. Table 4 provides an explanation of each competency type, as well as the four possible alignments of the various competency types.

This framework establishes the idea that team membership and task characteristics prescribe the type of competencies that will lead to its success. Skills targeted for training will be focused on the ability to work with specific or different individuals, or to work on specific or different types of tasks. Once the appropriate competencies and focus for training have been identified, then it becomes important to determine how best to train those skills.

\subsubsection{What is team training?: In spite of significant progress regarding what to} train, many present-day assumptions regarding how to train have no basis in research. Team training is more than just team building. Clearly the data imply that 
Table 4. Task and team competency types.

Task

Competency types

Task-specific competencies involve
performing teamwork behaviours

Team-specific competencies relate to for a specific task or situation (e.g. interaction required for a task, knowledge of the specific role responsibilities for a particular team, etc.)

Generic Task-generic competencies are transportable and can be used for other tasks (e.g. planning skills, interpersonal skills, etc.)

a specific team and influence the performance of that team only (e.g. knowledge of teammates' characteristics, team cohesion, etc.)

Team-generic competencies are, in principle, transportable from one team to another and can influence the performance of any team that an individual serves on (e.g. communication skills, attitudes toward teamwork, etc.)

\section{Competency alignments}

Task specificlteam specific: Needed when team membership is stable and the number of tasks is small. Examples: sports teams and some air crews/combat teams

Task specificlteam generic: Needed when team members perform a specific team task, but do not work consistently with the same teammates. Examples: firefighting team, air crews, or medical teams

Task genericlteam specific: Needed when team membership is stable, but the tasks vary. Examples: self-managed work teams or quality circles

Task genericlteam generic: Needed where team members work on a variety of teams, as well as on a variety of tasks. Examples: task forces or project teams

it is not enough to train individual responsibilities and simply hope that the team members will magically figure out how to operate as a team (Stout et al. 1994, McIntyre and Salas 1995, Salas and Cannon-Bowers 2000).

Training strategies should be grounded in theory and sound instructional principles. Salas and his colleagues have undertaken to formulate and empirically validate principles, guidelines, and specifications for team training (Swezey and Salas 1992a,b, Salas and Cannon-Bowers 1997, 2000). Team training is essentially 'a set of tools and methods that, in combination with required competencies and training objectives, form an instructional strategy' (Salas and Cannon-Bowers 2000: 5). Cognitive, behavioural, and affective competencies necessary for effective teamwork drive the training objectives. Those objectives combine with available resources (tools and methods) to shape the development of specific instructional strategies. Training tools include, but are not limited to, team task analysis, task simulation and exercises, and performance measurement and feedback. Methods for delivery may be information-based, demonstration-based, or practice-based, and may include lectures, video or multimedia presentations, demonstrations, guided practice, and role-playing (Salas and Cannon-Bowers 1997, 2000). The goal is to design and develop from these tools and methods specific instructional strategies for influencing team processes and outcomes. Representative instructional strategies that have been 
formulated in recent years are presented in table 5 (note that each of these strategies has demonstrated its effectiveness in the areas indicated).

4.3.2.1. Train the part or the whole?: Particularly problematic in the development of training strategies is the selection of 'part' versus 'whole' training methods. In part training, team members learn specific components of the task individually and sequentially, and then gradually integrate those skills until the entire task is mastered. In whole training, they are exposed to the entire task during all segments of the training procedure. Instructors must decide whether to (1) provide individual skills training that includes a focus on the interactive requirements of the team task (individual-whole training), (2) provide individual skills training that ignores the team context (individual-part training), (3) provide team skills training with specific focus on each individual's assigned subtask (team-part training) or (4) provide team skills training within the context of the team and its coordination and communication requirements (team-whole training). If high complexity and high organization characterize the team task, then the best strategy may be to combine the individualwhole and the team-whole approaches. Unfortunately, no standard exists for sequencing these two training types or for the establishing the appropriate ratio of each. It is hoped that future research will shed more light on when individual/team and part/whole training paradigms are most beneficial, and will demonstrate how task characteristics affect these relationships (Salas et al. 1992).

4.3.2.2. Performance feedback: Once training is implemented, performance feedback can become in the hands of team leaders one of the most influential tools for shaping the development of their teams. Team leaders should consider the amount, timeliness, focus, specificity, and sequencing of their feedback to team members. Ideally, that feedback is not delayed, but is given frequently and immediately after each significant team response, whether correct or incorrect. It focuses on the task and is directed to both the individual and to the team as a whole. It avoids emphasizing one characteristic of team performance at the expense of others. It focuses on only one aspect of task performance during early training

Table 5. Representative instructional strategies.

\begin{tabular}{|c|c|c|}
\hline Targeted skills & Representative strategies & References \\
\hline $\begin{array}{l}\text { Leadership/ } \\
\text { assertiveness }\end{array}$ & Team leader training & $\begin{array}{l}\text { Dyer (1984) } \\
\text { Tannenbaum et al. (1998) }\end{array}$ \\
\hline $\begin{array}{l}\text { Performance } \\
\text { monitoring/ } \\
\text { feedback }\end{array}$ & Guided team self-correction & $\begin{array}{l}\text { Blickensderfer et al. (1997a,b), } \\
\text { Smith-Jentsch et al. (1998), } \\
\text { Salas and Cannon-Bowers (2000) }\end{array}$ \\
\hline $\begin{array}{l}\text { Communication/ } \\
\text { coordination/ } \\
\text { adaptability/ } \\
\text { interpersonal } \\
\text { skills }\end{array}$ & $\begin{array}{l}\text { Crew resource management }(\mathrm{CRM}) \\
\text { Aircrew coordination training } \\
\text { (ACT) } \\
\text { Team adaptation and coordination } \\
\text { training } \\
\text { Cross training } \\
\text { Team dimensional training (TDT) }\end{array}$ & $\begin{array}{l}\text { Wiener et al (1993), Prince and Salas } \\
\text { (1993), Serfaty et al. (1998), Volpe et } \\
\text { al. (1996), Blickensderfer et al. } \\
\text { (1998), Smith-Jentsch et al. (1998a,b, } \\
\text { 1996a), Johnston et al. (1997) }\end{array}$ \\
\hline $\begin{array}{l}\text { Stress } \\
\quad \text { management }\end{array}$ & Stress exposure training & Driskell and Johnston (1998) \\
\hline Decision-making & Critical thinking training & Cohen et al. (1998) \\
\hline
\end{tabular}


sessions, but increases its scope to cover many aspects during later sessions. It increases in specificity with training, such that it reinforces gross aspects of performance during early phases of team training, then more specific aspects later on to 'fine tune' performance. Finally, it is sequenced so that individual feedback is given in initial training sessions, while feedback regarding overall performance is provided in later phases of training. As the number of interdependencies among team members increases, so does the importance of team feedback (Salas et al. 1992).

4.3.2.3. What are the instructional strategies?: Certain teamwork skills have presented considerable challenge to the development of instructional strategies. One such skill is the ability to learn on a continuous basis. Since learning is meant to be a continuous process, teams should be trained in techniques that stimulate continuous team growth. One of the strategies illustrated earlier — 'Guided Team SelfCorrection' - has successfully structured this type of training and made significant progress in meeting this particular challenge (Blickensderfer et al. 1997a,b, SmithJentsch et al. 1998b).

Progress has been slower in other areas, notably in instructional development for two very complex teamwork skills - shared SA and decision-making. If one accepts the idea that teams are information processing units, a notion advanced by Hinsz et al. (1997), then it becomes apparent that member interactions can enhance or degrade a group's ability to attend to, encode, store, retrieve, feedback, and ultimately learn from crucial task information. These interactions become the foundation for training in the areas of SA and decision-making.

$\mathrm{SA}$ relies on both individual and team mental models (Cannon-Bowers et al. 1993, Duncan et al. 1996, Stout et al. 1996). Each team member perceives one or more parts of the complex environment, and these perceptions must be integrated with those of fellow team-mates. The objective is for the team to share a common picture of the environment. To accomplish this, team members must voice communications that promote collective awareness of the surrounding environment, both internal and external to the team, and make timely and accurate reports of deviations from the norm or potential problems. Team leaders can continually update team members during times of stress to keep them abreast of rapidly changing priorities and performance objectives. Training that supports these abilities, as well as the development of shared perceptions of critical task and interpersonal dimensions will improve a team's SA ability.

Decision-makers must first recognize the problem and the need for action. Depending on their task environment, teams rely on controlled, analytic decisionmaking (e.g. problem-solving teams in an industrial environment) or on more automatic perceptual-cognitive processes (e.g. tactical decision-making teams, law enforcement or fire-fighting teams, emergency medical teams). The latter form of decision-making, called 'naturalistic decision-making' (Zsambok 1997) or 'recognition-primed decision-making' (Klein 1989, 1993), is prevalent in environments where performance is both resource and data-limited. In those environments, decisionmakers must maintain large amounts of information in memory under conditions of high workload and stress, and their decisions may be skewed by the lack of complete, error-free, unambiguous data. Because the situation itself either determines or constrains the response options, decision-makers in these environments typically make up to $95 \%$ of all decisions without considering alternatives (Klein 1989, Kaempf et al. 1996). If the situation appears similar to one that the decision-maker 
has previously experienced, the pattern will be recognized and the course of action is usually immediately obvious. Due to notable team failures in these types of environments (e.g. the 1988 Vincennes incident, in which the decision was made to launch a defensive missile against an Iranian airbus carrying 290 passengers, whose radar signal only moments before was misclassified as that of a hostile attacking fighter aircraft), efforts are currently underway to improve decision-making in these types of environments.

Because this type of decision-making relies heavily on the ability of decisionmakers to recognize important features/patterns within contexts, naturalistic approaches would promote the viability of training perceptual processes (Orasanu 1995). In fact, this approach parallels what researchers have discovered concerning the development of expertise. In short, novices tend to use more controlled, analytic approaches to reach their decisions. As they accumulate experience, they begin to switch between controlled and more automatic, perceptual-cognitive processes. By the time they become experts, they almost exclusively utilize the automatic perceptual processes (Klein and Hoffman 1993). Training for team members who must perform in naturalistic settings might focus on key novice/expert differences that have been identified, namely: (1) recognizing patterns, (2) making fine perceptual discriminations, (3) recognizing typicality and detecting anomalies, (4) mentally simulating future states and past states, (5) improvising and (6) adapting to events (Shanteau 1988, Klein and Hoffman 1993, Means et al. 1993).

An earlier referenced training strategy, 'Critical Thinking Training', represents a less common form of naturalistic decision-making called 'explanation-based reasoning' or story-generation (Cohen et al. 1998). In story-generation, the decision-maker attempts to evaluate the discrepancies between expectations and what actually happens by creating a reasonable hypothesis or story to explain it. As with recognition-primed decision-making, however, this type of reasoning is not exhaustive in the analytic tradition, but is fairly short and concise. It is usually implemented when pattern recognition fails or when time permits.

These two processes - feature-matching and story-generation - have been demonstrated to account for the majority of situation assessments and subsequent decisions made by decision-makers in environments which preclude the use of more controlled, analytic types of decision-making. In fact, Kaempf et al. (1993) demonstrated that in a sample of 183 decisions made by the Navy's commandlevel decision-makers in the Combat Information Centre of an Aegis cruiser, 87\% of the situation assessments were derived through feature matching and the remaining $13 \%$ were derived through story generation.

\section{Where does one go from here?}

While team research, especially in the last decade, has been fruitful, considerable work remains to be done. Several lines of investigation may be particularly beneficial (Salas et al. 1995, Salas and Cannon-Bowers 2000). Foremost, perhaps, are the implications of cognitive theory, for team performance. One needs to understand how teams function as information-processing units, that is, how knowledge is acquired, shared and acted on. How do individual team members contribute vital pieces to the problem-solving puzzle, and how do those contributions build shared mental models and promote SA? If one can understand this process, team performance measurement tools training can be shaped to capitalize on it. The next frontier in team measurement is to develop team assessment tools to capture 
cognitive phenomena. This is a must if progress is to be made understanding team functioning in complex systems. Related, and as stated above, is the need to improve task analysis for teams so that one may evaluate interdependence better among team members and the cognitive requirement. For a specific team, one needs to understand how much shared knowledge is required by that team's task interdependence, and what factors potentially moderate the relation between their shared knowledge and performance. Until one understands this interdependence, and the contributions both expected and required, it is impossible effectively to assess or train team performance. Improved team task analysis will facilitate the development of expert models needed for diagnostic purposes. Furthermore, task analysis, especially cognitive task analysis, is extremely time-consuming and painstaking in nature. One needs better tools to facilitate this process. One needs to improve the elicitation of knowledge from experts so that one can understand the subtleties, relationships, and interdependencies present in team tasks, and provide insights necessary to identify important training objectives.

Finally, how can one improve the diagnosticity of team performance measures? Interpreting the mass quantities of performance data (e.g. communications, keypress actions, eye movements, other physiological indicators) that are captured in some team settings, in some meaningful way is a daunting task at best. What knowledge requirements and behavioural skills lie behind those measures? It is vitally important that solid links are established between knowledge requirements, training objectives and performance indicators. This is particularly true for training simulations, both stand-alone and networked. Given the cost drivers in many modern operational settings, it is even more important that training resources be allocated efficiently. Automating the synthesis and interpretation of performance measurement data, as well as its collection, is also vital to many operational environments (e.g. military training situations). Solutions are needed to alleviate the labour intensive monitoring and evaluation so often necessary in team settings. Whether or not automation is present or feasible, one needs better measurement tools, particularly for unique team-related skills (e.g. its dynamic nature). If one considers that such tools would need to elicit and measure shared knowledge, then one can understand how seemingly formidable such a task would be.

Undoubtedly, the field of team research will present enormous challenges and opportunities in the years that lie ahead. Clearly, the answers to these and many other questions will show us the way to transform teams of experts into expert teams. Most importantly, they will empower teams to respond to the scope and complexity of the task demands that society has enlisted them to shoulder.

\section{Concluding remarks}

The progression of this concept has been traced from its inception 50 years ago to current thinking. It has been learnt that teamwork is the seamless integration of specific cognitive, behavioural and affective competencies that allow team members to adapt and optimize their performance. Researchers have made great strides in defining teams, in ascertaining how they mature and develop, and in differentiating their performance from that of individuals and groups. They have identified competencies that enable teams to meet their goals, and have developed effective techniques for capturing, measuring and teaching those skills. In terms of training, a considerable repertoire has been acquired from which to draw principles, guidelines and specifications to maximize success. Finally, researchers have considered ways to 
select better teams, to design better team tasks and to adapt automation to team settings.

\section{Acknowledgements}

The views expressed herein are those of the authors and do not reflect the official position of the organization to which they are affiliated.

\section{References}

Adams, M. J., Tenney, Y. J. and Pew, R. W. 1995, Situation awareness and the cognitive management of complex systems, Human Factors, 37, 85-104.

Adelman, L. Zirk, D. A., Lehner, P. E., Moffett, R. J. and Hall, R. 1986, Distributed tactical decision-making. Conceptual framework and empirical results, IEEE Transactions on Systems, Man, and Cybernetics, SMC-16, $794-805$.

Annetr, J. 1997, Analysing team skills, in R. Flin, E. Salas, M. Strub and L. Martin (eds), Decision-making Under Stress: Emerging Themes and Applications (Aldershot: Ashgate), $315-325$.

Baker, D. P. and Salas, E. 1992, Principles for measuring teamwork skills, Human Factors, 34, $469-475$.

Bandura, A. 1986, Social Foundations of Thought and Action (Englewood Cliffs: PrenticeHall).

Bass, B. M. 1980, Individual capability, team performance, and team productivity, in E. A. Fleischman and M. D. Dunnette (eds), Human Performance and Productivity (Hillsdale: Lawrence Erlbaum), 179-232.

Blickensderfer, E. L., Cannon-Bowers, J. A. and Salas, E. 1997a, Fostering shared mental models through team self-correction: theoretical bases and propositions, in $M$. Beyerlein, D. Johnson and S. Beyerlein (eds), Advances in Interdisciplinary Studies in Work Team, vol. 4 (Greenwich: JAI Press).

Blickensderfer, E. L., Cannon-Bowers, J. A. and Salas, E. 1997b, Training teams to selfcorrect: an empirical investigation. Paper presented at the 12th Annual Conference of the Society for Industrial and Organizational Psychology, St Louis, MO.

Blickensderfer, E. L., Cannon-Bowers, J. A. and Salas, E. 1998, Cross-training and team performance, in J. A. Cannon-Bowers and E. Salas (eds), Making Decisions Under Stress: Implications for Individual and Team Training (Washington, DC: American Psychological Association Press), 299-311.

Bowers, C. A., Deaton, J., Oser, R., Prince, C. and Kolb, M. 1993, The impact of automation on crew communication and performance, in Proceedings of the Seventh International Symposium on Aviation Psychology (Columbus: Ohio State University), 758 - 761.

Bowers, C. A., Oser, R. L., Salas, E. and Cannon-bowers, J. A. 1996, Team performance in automated systems, in R. Parasuraman and M. Mouloua (eds), Automation and Human Performance: Theory and Applications (Mahwah: Lawrence Erlbaum), 243-263.

Bowers, C. A., Urban, J. M. and Morgan, B. B. JR 1992, The Study of Crew Coordination and Performance in Hierarchical Team Decision Making. Report no. TR-92-01 (Orlando: University of Central Florida, Team Performance Laboratory).

Campion, M. A., Medsker, G. J. and Higgs, A. C. 1993, Relations between work group characteristics and effectiveness: implications for designing effective work groups, Personnel Psychology, 46, $823-850$.

Campion, M. A., Papper, E. M. and Medsker, G. J. 1996, Relations between work team characteristics and effectiveness: a replication and extension, Personnel Psychology, 49, $429-452$

Cannon-Bowers, J. A. and Salas, E. (eds) 1998, Making Decisions Under Stress: Implications for Individual and Team Training (Washington, DC: American Psychological Association).

Cannon-Bowers, J. A., Salas, E. and Converse, S. A. 1993, Shared mental models in expert team decision-making in N. J. Castellan, Jr (ed.), Individual and Group Decision Making (Hillsdale: Lawrence Erlbaum), 221-246.

Cannon-Bowers, J. A., Salas, E. and Grossman, J. D. 1991, Improving tactical decisionmaking under stress: research directions and applied implications. Paper presented at the International Applied Military Psychology Symposium, Stockholm. 
Cannon-Bowers, J. A., Tannenbaum, S. I., Salas, E. and Volpe, C. E. 1995, Defining team competencies: Implications for training requirements and strategies, in R. Guzzo and E. Salas (eds), Team Effectiveness and Decision Making in Organizations (San Francisco: Jossey Bass).

Cohen, M. S., Freeman, J. T. and Thompson, B. 1998, Critical thinking skills in tactical decision-making a model and a training strategy, in J. A. Cannon-Bowers and E. Salas (eds), Making Decisions Under Stress: Implications for Individual and Team Training (Washington, DC: American Psychological Association Press), 155-189.

Dickinson, T. L. 1969, The effects of work interaction and its interplay with task organization on team and member performance. Doctoral dissertation, Ohio State University, Dissertation Abstracts International, 30, 1937 - 1938.

Dieterly, D. L. 1988, Team performance requirements, in S. Gael (ed.), The Job Analysis Handbook for Business, Industry, and Government, vol. 1 (New York: Wiley), 486-492.

Driskell, J. E. and Johnston, J. H. 1998, Stress exposure training, in J. A. Cannon-Bowers and E. Salas (eds), Making Decisions Under Stress: Implications for Individual and Team Training (Washington, DC: American Psychological Association Press), 191-217.

Driskell, J. E. and Salas, E. 1992, Collective behaviour and team performance, Human Factors, 34, $277-288$.

Duncan, P. C., Rouse, W. B., Johnston, J. H., Cannon-Bowers, J. A., Salas, E. and Burns, J. J. 1996, Training teams working in complex systems: a mental model-based approach, in W. B. Rouse (ed.), Human/Technology Interaction in Complex Systems, vol. 8 (Greenwich: JAI Press), $173-231$.

Dwyer, D. J., Fowlkes, J. E., Oser, R. L., Salas, E. and Lane, N. E. 1997, Team performance measurement in distributed environments: the TARGETs methodology, in M. T. Brannick, E. Salas and C. Prince (eds), Assessment and Measurement of Team Performance: Theory, Research, and Application (Hillsdale: Lawrence Erlbaum), 137 154.

Dyer, D. J. 1984, Team research and team training: a state-of-the-art review, in F. A. Muckler (ed.), Human Factors Review: 1984 (Santa Monica: Human Factors Society), 285-323.

EndsLey, M. R. 1997, Level of automation: integrating humans and automated systems, in Proceedings of the Human Factors and Ergonomics Society 41st Annual Meeting (Santa Monica: Human Factors Society).

Entin, E., Serfaty, D. and Deckert, J. C. 1994, Team Adaptation and Coordination Training. Technical report, NAWCTSD Contract N61339-91-C-0142.

Fleishman, E. A. and Zaccaro, S. J. 1992, Toward a taxonomy of team performance functions, in R. W. Swezey and E. Salas (eds), Teams: Their Training and Performance (Norwood: Ablex), $31-56$.

Gentner, D. and Stevens, A. L. 1983, Mental Models (Hillsdale: Lawrence Erlbaum).

George, C. E., Hoak, G. and Boutwell, J. 1963, Pilot Studies of Team Effectiveness. Research memorandum no. 28, AD-627, 217 (US Army Infantry Human Research Unit, Human Resources Research Office, Ft Benning, GA).

Gersick, C. J. G. 1988, Time and transition in work teams: towards a new model of group development, Academy of Management Review, 31, 941.

Gladstein, D. L. 1984, Groups in context: A model of task group effectiveness, Administrative Science Quarterly, 29, $499-517$.

Goodman, P. S., Ravlin, E. and Schminke, M. 1987, Understanding groups in organizations, in L. L. Cummings and B. M. Staw (eds), Research in Organizational Behaviour, vol. 9 (Greenwich: JAI Press), $121-173$.

Gregorich, S. E., Helmreich, R. L. and Wilhelm, J. A. 1990, The structure of cockpit management attitudes, Journal of Applied Psychology, 75, 682-690.

Guzzo, R. A. and Salas, E. (eds) 1995, Team Effectiveness and Decision Making in Organizations (San Francisco: Jossey Bass).

Guzzo, R. A., Yost, P. R., Campbell, R. J. and Shea, J. P. 1994, Potency in groups: articulating the construct, British Journal of Social Psychology, 32, $87-106$.

Hackman, J. R. 1983, A Normative Model of Work Team Effectiveness. Technical report no. 2 (New Haven: Yale University).

Hackman, J. R. 1987, The design of work teams, in J. W. Lorsch (ed.), Handbook of Organizational Behaviour (Englewood Cliffs: Prentice-Hall), 315-342. 
Hackman, J. R. (ed.) 1990, Groups That Work (And Those That Do not): Creating Conditions for Effective Teamwork (San Francisco: Jossey-Bass).

Hackman, J. R. and Morris, C. G. 1975, Group tasks, group interaction process, and group performance effectiveness: a review and proposed integration, in L. Berkowitz (ed.), Advances in Experimental Social Psychology, vol. 8 (New York: Academic Press), $45-$ 99.

Hinsz, V. B., Tindale, R. S. and Vollrath, D. A. 1997, The emerging conceptualisation of groups as information processors, Psychological Bulletin, 121, 43-64.

Ilgen, D. R. 1999, Teams embedded in organizations: some implications, American Psychologist, 54, $129-139$.

Jentsch, F., Bowers, C., Redshaw, B., Bergen, H., Henning, J. and Holmes, B. 1995, Differential Effects of Automation on Team Performance, Workload, and Communications. Technical report (Orlando: Naval Air Warfare Centre Training Systems Division, University of Central Florida).

Johnston, J. H., Smith-Jentsch, K. A. and Cannon-Bowers, J. A. 1997, Performance measurement tools for enhancing team decision-making, in M. T. Brannick, E. Salas and C. Prince (eds), Team Performance Assessment and Measurement: Theory, Methods, and Applications (Hillsdale: Lawrence Erlbaum).

Kaempf, G. L., Klein, G., Thordsen, M. L. and Wolf, S. 1996, Decision-making in complex Naval command-and-contrd environments, Human Factors, 38, 220-231.

Kaempf, G. L., Wolf, S. and Miller, T. E. 1993, Decision-making in the Aegis combat information center, in Proceedings of the Human Factors and Ergonomics Society 37th Annual Meeting (Santa Monica, CA), 1107-1111.

KIDD, J. S. 1961, A comparison of one-, two-, and three-man work units under various conditions of workload, Journal of Applied Psychology, 45, 195-200.

Klein, G. A. 1989, Recognition-primed decisions, in W. Rouse (ed.), Advances in ManMachine Systems Research, vol. 5 (Greenwich: JAI Press), 47-92.

KLEIN, G. A. 1993, A recognition primed decision (RPD) model of rapid decision-making, in G. A. Klein, J. Orasanu, R. Calderwood and C. E. Zsambok (eds), Decision Making in Action: Models and Methods (Norwood: Ablex), 138-147.

Klein, G. A. and Hoffman, R. 1993, Seeing the invisible: perceptual-cognitive aspects of expertise, in M. Rabinowitz (ed.), Cognitive Science Foundations of Instruction (Hillsdale: Lawrence Erlbaum) 203-226.

Kleinman, D. L. and Serfaty, D. 1989, Team performance assessment in distributed decisionmaking, in Proceedings of the Symposium on Interactive Networked Simulation for Training (Orlando), $22-27$.

Klimoski, R. and Jones, R. G. 1995, Staffing for effective group decision-making: key issues in matching people and teams, in R. A. Guzzo, E. Salas and Associates (eds), Team Effectiveness and Decision Making in Organizations (San Francisco: Jossey-Bass), 291 332.

Kolodny, H. F. and Kiggundu, M. N. 1980, Towards the development of a sociotechnical systems model in woodlands mechanical harvesting, Human Relations, 33, 623-645.

McIntYRe, R. M. and SAlAs, E. 1995, Measuring and managing for team performance: emerging principles from complex environments, in R. Guzzo and E. Salas (eds), Team Effectiveness and Decision Making in Organizations (San Francisco: Jossey-Bass), 149-203.

Means, B., Salas, E., Crandall, B. and Jacobs, O. 1993, Training decision-makers for the real world, in G. A. Klein, J. Orasanu, R. Calderwood and C. E. Zsambok (eds), Decision Making in Action: Models and Methods (Norwood: Ablex).

Meister, D. 1985, Behavioural Foundations of System Development. 2nd edn (Malabar: Robert E. Krieger).

Modrick, J. A. 1986, Team performance and training, in J. Zeidner (ed.), Human Productivity Enhancement: Training and Human Factors in Systems Design, vol. 1 (New York: Praeger), $130-166$.

Morgan, B. B. Jr, Coates, G. D., Alluizi, E. A. and Kirby, R. H. 1978, The Team-Training Load as a Parameter of Effectiveness for Collective Training in Units. ITR-78-14, DTIC no. AD A063 135 (Norfolk: Old Dominion University). 
Morgan, B. B. Jr, Glickman, A. S., Woodward, E. A., Blaiwes, A. S. and Salas, E. 1986, Measurement of Team Behaviours in a Navy Environment. NTSC technical report TR86-014 (Orlando: Naval Training Systems Centre).

Morgan, B. B. Jr, Herschler, D. A., Wiener, E. L. and Salas, E. 1993, Implications of automation technology for aircrew coordination performance, in W. B. Rouse (ed.), Human/Technology Interaction in Complex Systems, vol. 6 (Greenwich: JAI Press), $105-$ 136.

Morgan, B. B. JR, Salas, E. and Glickman, A. S. 1994, An analysis of team evolution and maturation. Journal of General Psychology, 120, 277-291.

Morgeson, F. P., Aiman-Smith, L. D. and Campion, M. A. 1997, Implementing work teams: Recommendations from organizational behaviour and development theories, in M. M. Beyerlein, D. A. Johnson and S. T. Beyerlein (eds), Advances in Interdisciplinary Studies of Work Teams, 4, $1-44$.

Morrison, J. G., Kelly, R. T., Moore, R. A. and Hutchins, S. G. 1998, Implications of decision-making research for decision support and displays, in J. A. Cannon-Bowers and E. Salas (eds), Making Decisions Under Stress: Implications for Individual and Team Training (Washington, DC: American Psychological Association Press), 375-406.

Mosier, K. L. and SkitKa, L. J. 1996, Human decision-making and automated decision aids: made for each other?, in R. Parasuraman and M. Mouloua (eds), Automation and Human Performance: Theory and Applications (Mahwah: Lawrence Erlbaum), $201-220$.

Mullen, B. and Copper, C. 1994, The relation between group cohesiveness and performance: an integration, Psychological Bulletin, 115, 210-217.

Naylor, J. C. and Briggs, G. E. 1965, Team-training effectiveness under various conditions, Journal of Applied Psychology, 49, 223 - 229.

NAYlor, J. C. and Dickinson, T. L. 1969, Task structure, work structure, and team performance, Journal of Applied Psychology, 53, 167-177.

Nivea, F., Fleishman, E. A. and Reick, A. 1978, Team Dimensions: Their Identity, Their Measurement, and Relationships. Final technical report, Contract DAH19-78-C-0001 (Washington, DC: Advance Resources Research Organization).

Orasanu, J. 1990, Shared mental models and crew performance. Paper presented at the 34th Annual Meeting of the Human Factors Society, Orlando.

Orasanu, J. 1995, Training for aviation decision-making the naturalistic decision-making perspective, in Proceedings of the Human Factors and Ergonomics Society 39th Annual Meeting (Santa Monica, CA).

Orasanu, J. and Salas, E. 1993, Team decision-making in complex environments, in G. A. Klein, J. Orasanu, R. Calderwood and C. Zsambok (eds), Decision Making in Action: Models and Methods (Norwood: Ablex), 327-345.

Oser, R. L., McCallum, G. A., Salas, E. and Morgan, B. JR 1989, Toward a Definition of Teamwork: An Analysis of Critical Team Behaviour. NTSC technical report no. 90-009 (Orlando: Naval Training Systems Centre).

Pearce, J. A. and Ravlin, E. C. 1987, The design and activation of self-regulating work groups, Human Relations, 40, $751-782$.

Prince, C., Chidester, T. R., Bowers, C. and Cannon-Bowers, J. 1992, Aircrew coordination: achieving teamwork in the cockpit, in R. W. Swezey and E. Salas (eds), Teams: Their Training and Performance (Norwood: Ablex), 329-353.

Prince, C. and Salas, E. 1993, Training and research for teamwork in the military aircrew, in E. L. Wiener, B. G. Kanki and R. L. Helmreich (eds), Cockpit Resource Management (Orlando: Academic Press), $337-366$.

Roby, T. B. and Lanzetta, J. T. 1957a, A Replication Study of Work Group Structure and Task Performance. DTIC no. AD 134205 (Air Force Personnel and Training Research Centre, Lackland Air Force Base, TX).

Roby, T. B. and Lanzetta, J. T. 1957b, Conflicting principles in man-machine system design, Journal of Applied Psychology, 41, 170-178.

Rouse, W. B. and Morris, N. M. 1986, On looking into the black box: prospects and limits in the search for mental models, Psychological Bulletin, 100, 349-363.

Ruffell-Smith, H. P. 1979, A Simulator Study of the Interaction of Pilot Workload with Errors. NASA technical report no. TM-78482 (Moffett Field: National Aeronautics and Space Administration, Ames Research Centre). 
Rumelhart, D. D. and Ortony, A. 1977, The representation of knowledge in memory, in R. C. Anderson and R. J. Spiro (eds), Schooling and the Acquisition of Knowledge (Hillsdale: Lawrence Erlbaum), 99 - 135.

Salas, E., Bowers, C. A., Cannon-Bowers, J. A. 1995, Military team research: 10 years of progress, Military Psychology, 7, 55-75.

Salas, E. and Cannon-Bowers, J. A. 1997, Methods, tools, and strategies for team training, in M. A. Quinones and A. Ehrenstein (eds), Training for a Rapidly Changing Workplace: Applications of Psychological Research (Washington, DC: American Psychological Association), $249-279$.

Salas, E. and Cannon-Bowers, J. A. 2000, The anatomy of team training, in L. Tobias and D. Fletcher (eds), Handbook on Research in Training (New York: Macmillan) (in press).

Salas, E., Dickinson, T. L., Converse, S. and Tannenbaum, S. I. 1992, Toward an understanding of team performance and training, in R. W. Swezey and E. Salas (eds), Teams: Their Training and Performance (Norwood: Ablex), 3-29.

Serfaty, D., Entin, E. and Johnston, J. H. 1998, Team coordination training, in J. A. CannonBowers and E. Salas (eds), Making Decisions Under Stress: Implications for Individual and Team Training (Washington, DC: American Psychological Association Press), 221 245.

Shanteau, J. 1988, Psychological characteristics and strategies of expert decision-makers, Acta Psychologica, 68, $203-215$.

Shea, G. P. and Guzzo, R. A. 1987, Groups as human resources, in K. M. Rowland and G. R. Ferris (eds), Research in Personnel and Human Resources Management, vol. 5 (Greenwich: JAI Press), 323-356.

Shiflett, S. C., Eisner, E. J., Price, S. J. and Schemmer, F. M. 1982, The Definition and Measurement of Team Functions. Final report (Bethesda: Advanced Research Resources Organization).

Smith, P. C. and Kendall, L. M. 1963, Retranslation of expectations: an approach for the construction of unambiguous anchors for rating scales, Journal of Applied Psychology, 47, $149-155$.

Smith-Jentsch, K. A., Johnston, J. H. and Payne, S. C. 1998a, Measuring team-related expertise in complex environments, in J. A. Cannon-Bowers and E. Salas (eds), Making Decisions Under Stress: Implications for Individual and Team Training (Washington, DC: American Psychological Association), 61-87.

Smith-Jentsch, K. A., Payne, S. C. and Johnston, J. H. 1996a, Guided team self-correction: a methodology for enhancing experiential team training, in K. A. Smith-Jentsch (Chair), When, how and why does practice make perfect? Paper presented at the 11th Annual Conference of the Society for Industrial and Organizational Psychology, San Diego.

Smith-Jentsch, K. A., Salas, E. and Baker, D. 1996b, Training team performance-related assertiveness, Personnel Psychology, 49, 909-936.

Smith-Jentsch, K. A., Zeizig, R. L., Acton, B. and McPherson, J. A. 1998b, Team dimensional training: a strategy for guided team self-correction, in J. A. Cannon-Bowers and E. Salas (eds), Making Decisions Under Stress: Implications for Individual and Team Training (Washington, DC: American Psychological Association), 271 - 297.

Steiner, I. D. 1972, Group Processes and Productivity (New York: Academic Press).

Stout, R. J., Cannon-Bowers, J. A. and Salas, E. 1996, The role of shared mental models in developing team situational awareness: implications for training, Training Research Journal, 2, $85-116$.

Stout, R. J., Salas, E. and Carson, R. 1994, Individual task proficiency and team process: what's important for team functioning Military Psychology, 6, 177-192.

Sundstrom, E. and Altman, I. 1989, Physical environments and work-group effectiveness, in L. L. Cummings and B. M. Shaw (eds), Research in Organizational Behaviour, vol. 11 (Greenwich: JAI Press), 175-209.

Sundstrom, E., De Meuse, K. P. and Futrell, D. 1990, Work teams: applications and effectiveness, American Psychologist, 45, 120-133.

Swezey, R. W., Llaneras, R. E. and Salas, E. 1992, Ensuring teamwork: a checklist for use in designing team training programs, Performance and Instruction, 31, 33 - 37. 
Swezey, R. W., Owens, J. M. Bergondy, M. L. and SAlas, E. 1998, Task and training requirements analysis methodology (TTRAM): an analytic methodology for identifying potential training uses of simulator networks in teamwork-intensive task environments, Ergonomics, 41, $1678-1697$.

Swezey, R. W. and Salas, E. 1992a, Guidelines for use in team-training development, in R. W. Swezey and E. Salas (eds), Teams: Their Training and Performance (Norwood: Ablex), $219-245$.

Swezey, R. W. and Salas, E. (eds) 1992b, Teams: Their Training and Performance (Norwood: Ablex).

Tannenbaum, S. I., Beard, R. L. and Salas, E. 1992, Team building and its influence on team effectiveness: an examination of conceptual and empirical developments, in K. Kelley (ed.), Issues, Theory, and Research in Industrial/ Organization Psychology (Amsterdam: Elsevier), $117-153$.

Tannenbaum, S. I., Smith-Jentsch, K. A. and Behson, S. J. 1998, Training team leaders to facilitate team learning and performance, in J. A. Cannon-Bowers and E. Salas (eds), Making Decisions Under Stress: Implications for Individual and Team Training (Washington, DC: American Psychological Association Press), 247-270.

Thornton, C. Braun, C., Bowers, C. A. and Morgan, B. JR 1992, Automation effects in the cockpit: a low-fidelity investigation, in Proceedings of the 36th Annual Meeting of the Human Factors Society (Santa Monica, CA), 30 - 34.

Trow, D. B. 1964, Teamwork Under Turnover and Succession. Technical report no. 2, Office of Naval Research contract no. 3679 (00), project NR 170-331, DTIC no. AD 601816 (Endicott: Harpur College).

Urban, J. M., Bowers, C. A., Cannon-Bowers, J. A. and Salas, E. 1995, The importance of team architecture in understanding team processes, in M. Beyerlein (ed.), Advances in Interdisciplinary Studies in Work Teams, vol. 2 (Greenwich: JAI Press), 205-228.

Volpe, C. E., Cannon-Bowers, J. A., Salas, E. and Spector, P. 1996, The impact of cross training on team functioning, Human Factors, 38, 87-100.

West, M. A. 1996, Handbook of Work Group Psychology (New York: Wiley).

WIENER, E. L. 1993, Crew coordination and training in the advanced-technology cockpit, in E. L. Wiener, B. G. Kanki and R. L. Helmreich (eds), Cockpit Resource Management (San Diego: Academic Press), 199-229.

Wiener, E. L., Chidester, T. R., Kanki, B. G., Palmer, E. A., Curry, R. E. and Gregorich, S. E. 1991, The Impact of Cockpit Automation on Crew Coordination and Communication: I. Overview, LOFT Evaluations, Error Severity, and Questionnaire Data. Technical report no. NASA-CR-177587 (Moffett Field: NASA Ames Research Centre).

Wiener, E. L., Kanki, B. J. and Helmreich, R. L. (eds) 1993, Cockpit Resource Management (San Diego: Academic).

Zachary, W., Bilazarian, P., Burns, J. and Cannon-Bowers, J. A. 1997a, Advanced embedded training concepts for shipboard systems (CD-ROM), in Proceedings of the 19th Annual Interservicel Industry Training, Simulation, and Education Conference (Orlando: National Training Systems Association), 670-679.

Zachary, W. and Cannon-Bowers, J. A. 1997, Guided practice - a new vision for intelligent embedded training, in Proceedings of the Human Factors and Ergonomics Society 41st Annual Meeting (Santa Monica, CA).

Zachary, W., Ryder, J., Hicinbothom, J. and Bracken, K. 1997b, The use of executable cognitive models in simulation-based intelligent embedded training, in Proceedings of the Human Factors and Ergonomics Society 41st Annual Meeting (Santa Monica, CA).

Ziller, R. C. 1963, The Effects of Changes in Group Composition on Group Performance. Final report, grant no. AFOSR 62-95, DTIC no. AD 413965 (Newark: University of Delaware).

Zsamboк, C. E. 1997, Naturalistic decision-making. where are we now?, in C. E. Zsambok and G. Klein (eds), Naturalistic Decision Making (Mahwah: Lawrence Erlbaum). 